\title{
Workplace Violence against Nurses Working in Emergency Departments at Public Hospitals Lahore
}

\author{
Salman Ijaz*, Afsar Ali, Naseem Rooman, Hafiza Anam khadim \\ National College of Nursing, The University of Lahore, Lahore, Pakistan.
}

\begin{abstract}
Background: Work place violence is an alarming and devastating issue worldwide particularly in the emergency departments. Incident of work place violence is common towards nurses in health care settings. Nurses are more prone to workplace violence due to lack of respect towards nursing profession in Pakistani society and the nature of work performed by the nurses.
\end{abstract}

Objective: The main purpose of this study was to assess the prevalence of work place violence including physical and non physical and bring awareness about work place violence among nurses at the emergency departments of health care systems.

Methodology: A cross sectional descriptive survey was performed to assess the prevalence of work place violence at tertiary care hospitals of Lahore. A convenient sample of $\mathrm{n}=147$ was used to collect the data. A structured standardized adopted questionnaire was used to collect data. The questionnaire consisted demographic, physical and non physical variables. The data was collected from Jinnah and services hospital Lahore. The data was analyzed on SPSS version 21.

Results: It was found that $77.55 \%$ stated that they are not exposed to physical violence last 12 months, $13.6 \%$ said once, $7.48 \%$ said $2-3$ times and $1.3 \%$ stated they have been exposed 4-5 times during last year. On the other hand the participants exposed to Nonphysical violence in last 12 months, $12.93 \%$ stated that they are not exposed to physical violence last 12 months, $25.85 \%$ said once, $40.82 \%$ said $2-3$ times and $19.73 \%$ stated they have been exposed 4-5 times during last year.

Most recent physical incident in which $10.20 \%$ of incidents were happened at resuscitation room $2.04 \%$ at waiting room and $10.20 \%$ in treatment room. The most recent nonphysical incident in which $38.10 \%$ of incidents were happened at resuscitation room $0.68 \%$ in triage $12.24 \%$ at waiting room and $37.41 \%$ in treatment room $0.68 \%$ in other places.

Conclusion: The physical violence prevalence was found less that the nonphysical violence, but Physical violence is more threatening than the nonphysical violence.

Keywords: Nurses, Emergency department, Physical violence, Non physical violence, Violence by patients, Violence by patients' relatives, Violence by Coworkers.

\section{INTRODUCTION}

Many countries of the world are encountered by Workplace physical violence almost in every field of employment which is a real matter of concern [1]. The occurrence of violence at work place has become a serious threat to the safety and security of employees; exploit their dignity, further leads to lower wellbeing among them and this end up with an unhappy status of the workers. It most of the times puts life in troubles and may lead to death like serious consequences among the health care workers [2]. Work place violence is considered among the leading causes of deaths at the US among women who serve outside in hospitals or any other services. The lethal consequences of work place violence such as severe injuries have greater impact on life and cannot be underestimated by any state or country of the world [3].

Health care profession has even more severe consequences

*Address correspondence to this author at the National College of Nursing, The University of Lahore, Lahore, Pakistan.

E-mail: salmanijaz323@gmail.com from work place violence which appears as a major issue globally important in terms of violence against nurses and other health professionals at their work place. These violence may include verbal abuse from patients and their relative, physical violence like hitting and beating, and sexual harassment etcetera [4]. The verbal violence has the highest occurrence of all work place violence. Moreover, Nurses are exposed to work place violence more than any other health care discipline because they remain in contact with patients and their families for all the times [5].

Some highlighted areas at the hospital are at greater risk of work place violence. These areas include the Psychiatric units, emergency departments of the hospital, and sometimes high dependency units of health care systems. The occurrence of violence in the psychiatric wards and the emergency departments is very common which is almost $100 \%$ and more than any other department in the hospital [6].

Work place violence is defined as "Occurrence of such events where the nurses and other health care workers are abused

www.njhsciences.com 
verbally, assaulted or harassed sexually, or might face assaulted in their work place environment. This may become a threat to their safety and security, and their health and wellbeing becomes a questionable [7]. The effects of work place violence is not limited to nurses only, rather it also have equal impact on doctors and other health care workers [8].

It is suggested that the incidence of verbal abuse is rising day by day and reaching almost $100 \%$ nurses at the emergency departments of many hospitals. According to the American Nurses Association, very few nurses are safe from the work place violence (Less than 20\%). There is lack of moral or legal support from the institutions to prevent violence among nurses which leads to dissatisfaction among them [9].

Work place violence is very common everywhere in every hospital against nurses but it is on the top in low socioeconomic developing countries of the world. Pakistan is one of such countries having high incidence of work place violence among nurses at work environment. There is also another issue of poor reporting, lack of documentation and unpublished status of such violence in the health care setups. Such high incidences of work place violence among nurses put the managements of different organizations in the challenging situations [6].

Despite of so many bad consequences of work place violence among nurses, it is still under reported and under rated issue. This lack of reporting may be because of fear, stigma and blame of being harassed. More seriously, the society might think that the nurses are made to bear such violence as part of their care that is why they are expected to tolerate it [5].

Findings of a study reveals that incidence of verbal violence was $(63.9 \%)$, which was almost five times more than physical violence $(11.9 \%)$ at the emergency department among nurses in the last 12 months of period. Verbal violence at the emergency department was mainly by the patients against nurses then secondly by their family members and relatives. The rate of physical violence was also high from patients and their family members. Afternoon shift was found to have more work place violence at the emergency departments due to increased patients inflow [10].

According to another study verbal violence was very high (86\%) among nurses at the emergency departments. Threats were also found high about (35\%) of among the nurses' participants. Physical abuse was also found among the nurses, done by patients and their families but it was lower than that of verbal assault. No difference of violence exposure was found between males and females or based on the specialty such as medical and surgical. However very few respondents were from emergency to have a meaningful comparison [11].

This paper presents workplace violence towards nurses as a major issue in the context of health care settings in Pakistan.
Here some characteristics of violence against the emergency nurses will be highlighted; some problems will be analyzed from different ethical professional and legal perspectives. Here some physical and psychological consequences of work place violence will be highlighted too.

\section{Aims of the Study}

1. To assess the prevalence of violence against nurses working in the emergency departments of public tertiary hospitals Lahore.

2. To identify the types of violence against nurses working in the emergency departments of public tertiary hospitals Lahore.

\section{Significance of the Study}

Workplace violence is an issue of international health care among the workers at all departments of the health care systems but more sever at the emergency departments. Direct violence or indirect violence which may be physical or non-physical violence among nurses at the emergency departments might cause negative consequences in the future of nurses. If nurses of emergency department be aware of the types and causes of violence they can decrease the bad consequences and will avoid negative effect on the quality of health care providers and patients. The decrease in the productivity of nursing care will be minimized, negative impact on nurses whether it is physically or psychologically will be controlled. This may help the nurses to resolve violence related issues and continue a peaceful job life ahead.

\section{METHODS}

\section{Setting}

This study was conducted among the nurses at the Emergency Departments of two public tertiary care hospitals Lahore. They are the Jinnah Hospital Lahore and Services Hospital Lahore.

\section{Research Design}

A descriptive cross-sectional study design was used to conduct this study. Data about the violence against emergency department nurses was collected at one point in time with the help of a questionnaire.

\section{Population}

The study was conducted among the nurses. The population for this study was all nurses who are working in emergency departments of the selected hospitals, the Jinnah Hospital and the Services Hospital Lahore.

\section{Sampling}

Sampled was selected from the emergency departments of two public hospitals through convenient sampling methods. $\mathrm{n}$ 
$=75$ was selected from Jinnah Hospital while remaining 72 nurses was selected from services hospital emergency department.

\section{Research Instrument}

A self-administered standardized adopted questionnaire was used to collect the data. The questionnaire adopted from a study 'Work place violence against nurses working in the emergency department of in Saudi Arabia' by Fuaad Ali Alshehri [10].

The first section of the questionnaire consisted off the demographic information about the age, gender, education and working experience of the participants. The second and third parts of the questionnaire discussed the physical and nonphysical violence among nurses at the emergency departments. The participants of the study were asked to fill the questionnaire of work place violence.

\section{Data Gathering Procedure}

The questionnaire was distributed to the participants in printed form where they answered all the question according to their own understanding. A time of about 30 minutes was given to fill the questionnaires. Then the filled questionnaires were collected.

\section{Methods Used to Analyze Data}

The data was put into the SPSS version 21. The results were processed and analyzed with the help of graphs, tables in the form of frequencies, averages and percentages.

\section{Study Timeline}

The data was collected from February, 2018 to April, 2018.

\section{Ethical Consideration}

An approval was taken from the committee of national college of nursing. Then permission was taken from the heads of the study setting such as Head of Jinnah hospital and Head of the Services hospital. A written permission was taken from each individual participant of the study. Each participant was provided with the questionnaire with an informed consent which was explained the purposes and significance of the study. The study participants were assured that their names will be kept confidential. Their participation was fully volunteer and can withdraw at any time.

\section{RESULTS}

\section{Profile of the Respondents}

Respondents were taken from different selected groups of Jinnah and Services hospital Lahore.

Table 1. Demographic Information.

\begin{tabular}{|c|c|c|}
\hline Variables & Number (n) & \% \\
\hline Gender & 10 & 6.8 \\
Male & 137 & 93.2 \\
Female & & \\
\hline Age & 15 & 10.2 \\
Less than 25 years & 78 & 53.1 \\
26-30 years & 41 & 27.9 \\
31-35 years & 9 & 6.1 \\
36-40 years & 4 & 2.7 \\
Above 40 years & 28 & 19.05 \\
Education: & 59 & 40.14 \\
Nursing Diploma & 60 & 40.81 \\
Diploma plus specialization & 0 & 0 \\
BSN/PRN BSN & & \\
MSN/MPH & 77 & 52.4 \\
\hline Experience & 51 & 34.7 \\
1-5 years & 15 & 10.2 \\
6-10 years & 4 & 2.7 \\
11-15 years & & \\
Above 15 years & & \\
\hline
\end{tabular}

Table 1 shows about the gender of participants that were $6.80 \%$ were male and $93.20 \%$ was female. Result also shows the age of the participants of study from which $10.2 \%$ were less than 25 years \& 53.1\% were between 26 to 30 years $27.9 \%$ were between the age of 31 to 35 years $6.1 \%$ were between the age of 36 to 40 years and $2.7 \%$ participants of study were more than 40 years of age. It was also found that the education level of the study participants from which $19.05 \%$ were only have general nursing diploma $40.14 \%$ of study participants having specialization as well $40.81 \%$ have the degree of generic BSN and post RN BSN degree.

Table 2. Prevalence of Physical and Non-Physical Violence among Nurses.

\begin{tabular}{|c|c|c|c|c|}
\hline Variables & \multicolumn{2}{|c|}{ Physical Violence } & \multicolumn{2}{|c|}{ Non-Physical Violence } \\
\hline Never & 114 & 77.6 & 19 & 12.9 \\
\hline 2-3 Times & 11 & 7.50 & 60 & 40.8 \\
\hline 4-5 times & 2 & 1.3 & 29 & 19.7 \\
\hline
\end{tabular}


Table 2. (Continued)

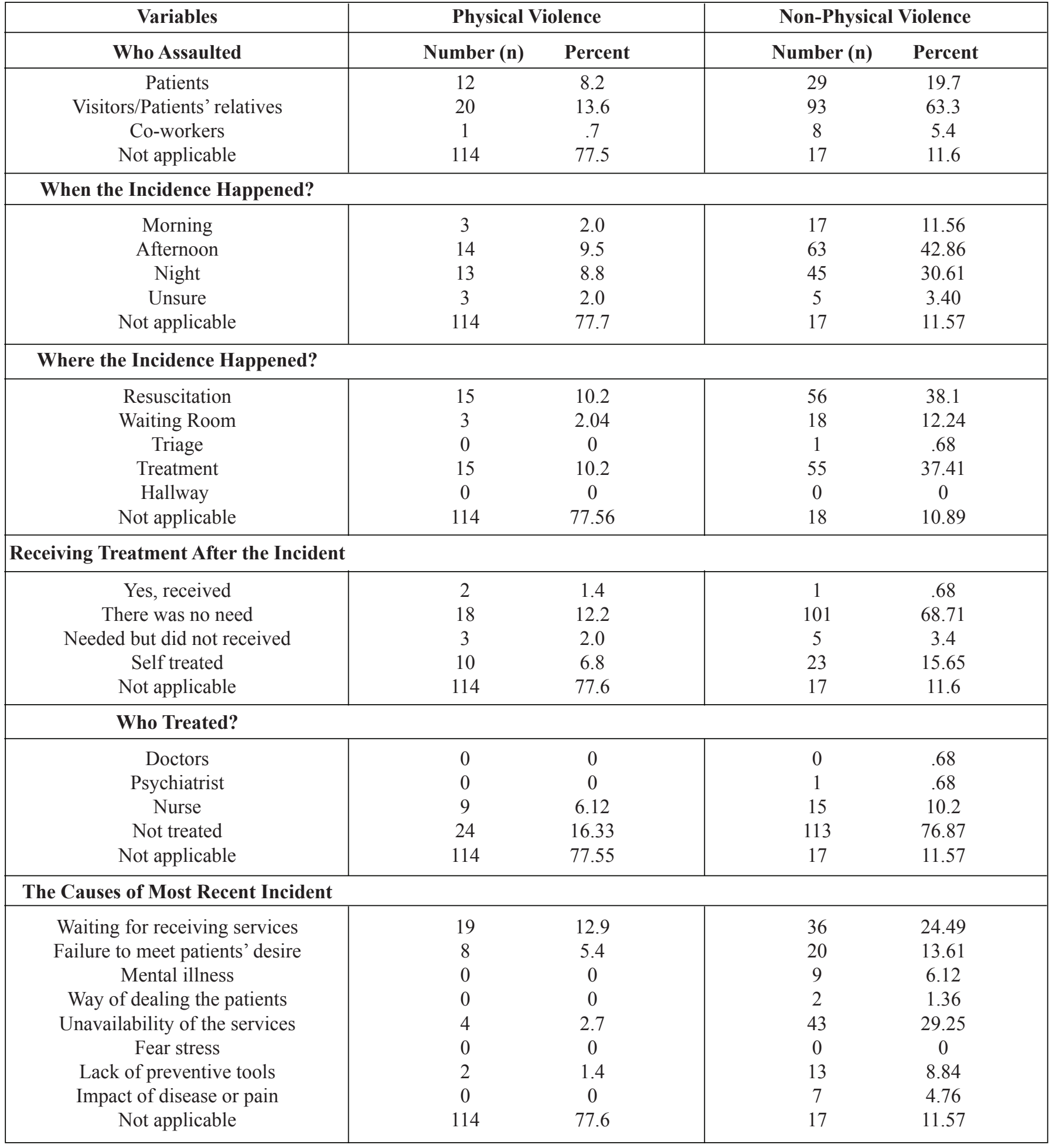

Table 2 shows that in response for how many times the participants exposed to physical violence in last 12 months. It was found that $77.6 \%$ stated that they are not exposed to physical violence last 12 months, $13.6 \%$ said once, $7.50 \%$ said 2-3 times and 1.3\% stated they have been exposed 4-5 times during last year. On the other hand the participants exposed to Nonphysical violence in last 12 months, $12.90 \%$ stated that they are not exposed to physical violence last 12 months, $25.90 \%$ said once, $40.80 \%$ said $2-3$ times and $19.70 \%$ stated they have been exposed 4-5 times during last year. The type of physical assault the study participants was asked and $4.08 \%$ of participants had experience beating, $9.52 \%$ experience pushing, $6.12 \%$ of study participants had experience slapping, $1.36 \%$ pinching, $1.36 \%$ shooting, and 
not applicable for $77.56 \%$ of study participants. Similarly about types of nonphysical assault the study participants were exposed to, $50.3 \%$ of participants had experience threats, $36.1 \%$ experience verbal abuse and $2.0 \%$ of study participants had experience sexual harassment/abuse, and not applicable for $11.6 \%$ of study participants. Regarding the physical assaulters to staff from which $8.2 \%$ were patients, $13.60 \%$ were relatives of patients, $0.7 \%$ were coworkers of the staff and not applicable for $77.50 \%$ participants. About the assaulters of nonphysical at staff from which $19.7 \%$ were patients, $63.3 \%$ were relatives of patients, $5.4 \%$ were coworkers of the staff and not applicable for $11.6 \%$ participants. It was also found that $2.0 \%$ incidents happened at morning shift $9.5 \%$ at evening $8.8 \%$ at night shift and not applicable for $77.7 \%$ of study participants in terms of physical violence. Where as in nonphysical violence $11.56 \%$ incidents happened at morning shift $42.86 \%$ at evening $30.61 \%$ at night shift $3.40 \%$ participants was not sure about timing of the incident and not applicable for $11.57 \%$ of study participants.

Most recent physical incident in which $10.20 \%$ of incidents were happened at resuscitation room $2.04 \%$ at waiting room and $10.20 \%$ in treatment room and this question was not applicable for $77.56 \%$ of participants. The most recent nonphysical incident in which $38.10 \%$ of incidents were happened at resuscitation room $0.68 \%$ in triage $12.24 \%$ at waiting room and $37.41 \%$ in treatment room $0.68 \%$ in other places and this question was not applicable for $10.89 \%$ of participants.

Furthermore, to physical violence $1.4 \%$ said yes received treatment, $12.2 \%$ not need, $2.0 \%$ not received and $6.80 \%$ self-treated and this question was not applicable for $77.6 \%$ of study participants. Similarly in nonphysical violence, $0.68 \%$ said yes received treatment, $68.71 \%$ no need, $3.40 \%$ not received and $15.65 \%$ self-treated. Result also shows that percentage by whom physical violence victim was treated $6.12 \%$ was treated by nurse $16.33 \%$ not treated and not applicable for $77.55 \%$ of study participants. It was also found in nonphysical violence that victim was treated $10.20 \%$ was treated by nurse, $0.68 \%$ by psychiatrist, $0.68 \%$ by others $76.87 \%$ not treated and not applicable for $11.57 \%$ of study participants. The Findings also show the percentage of the cause of most recent incident from which $12.9 \%$ of participants said that it was due to waiting for services $5.4 \%$ was unable to meet patients desire $2.7 \%$ was due to unavailability of services $1.4 \%$ was due to lack of preventive tools and not applicable for $77.6 \%$ of study participants. The cause of most recent nonphysical incidents from which $24.49 \%$ of participants said that it was due to waiting for services $13.61 \%$ was unable to meet patients desire $6.12 \%$ was due to mental illness $1.36 \%$ was due to way of dealing with patients $29.25 \%$ was due to unavailability of services $8.84 \%$ was due to lack of preventive tools $4.76 \%$ said that it was due to impact of disease or pain and not applicable for $11.57 \%$ of study participants.

Table 3. Multiple Summary of the Physical Violence.

\begin{tabular}{|c|c|c|}
\hline Variables Category & \multicolumn{2}{|c|}{} \\
\hline Type of physical Violence & $\mathbf{N}$ & $\mathbf{\%}$ \\
\hline Beating & 6 & 4.08 \\
Pushing & 14 & 9.52 \\
Slapping & 9 & 6.12 \\
Kicking & 0 & 0 \\
Biting & 0 & 0 \\
Pinching & 2 & 1.36 \\
Shooting & 2 & 1.36 \\
Stabbing & 0 & 0 \\
Not applicable & 114 & 77.56 \\
\hline
\end{tabular}

Table 3 suggests that $4.1 \%$ of the study participants had Beating experience, $9.5 \%$ experienced pushing, 6.9\% faced slapping, no kicking or biting was found, pinching and shooting was $1.4 \%$ each, while the rest of $77 \%$ had no experienced of physical violence.

Table 4. Summary of Nonphysical Violence.

\begin{tabular}{|c|c|c|}
\hline Variables Category & \multicolumn{2}{|c|}{} \\
\hline Type of Nonphysical Assault & N & \% \\
\hline Threats & 74 & 50.3 \\
Verbal abuse/Harassment & 53 & 36.1 \\
Sexual Abuse/Harassment & 3 & 2.0 \\
Not applicable & 17 & 11.6 \\
\hline
\end{tabular}

Table 4 findings indicate that about $50.3 \%$ of the study participants had faced threats as nonphysical violence, $36.1 \%$ experienced Verbal abuse/Harassment, while 2\% have experience Sexual Abuse/Harassment and 11.6\% faced no any nonphysical violence during last 1 year.

\section{DISCUSSION}

This current study findings suggest that physical violence among the nurses at emergency department was among $22.5 \%$ participants overall where $4.1 \%$ of the study participants had Beating experience, pushing from patients relative or patients was $9.5 \%, 6.9 \%$ nurses faced slapping from attendants. Furthermore pinching and shooting among nurses was experienced by $1.4 \%$ each. It is obvious that a good majority of the nurses $77.5 \%$ were not exposed to physical violence from patients and their relatives. The prevalence of nonphysical violence in the current study survey was found very high that is among $88.4 \%$ nurses. Here verbal threats were experienced by $50.3 \%$ of the study participants' nurses, verbal abuse and harassment was experienced by $36.1 \%$ nurses. The sexual assault and violence which is the serious one, was faced by $2 \%$ of the nurses. There were $11.6 \%$ nurses who faced no any kind of nonphysical violence during last 1 year. 
The current study findings were compared with previous study findings, where in a previous study the verbal violence was found similar that is $86 \%$ of the nurses and health care workers faced non-physical violence at the emergency departments. Similarly there was lower physical violence as compare to the non-physical violence which seems to be agreement with this current study findings. Furthermore they also checked the difference of prevalence between males and females and found no difference but in this current study the difference was not measured. However very few respondents were from emergency to have a meaningful comparison [11].

Another study also found a high prevalence of nonphysical violence and observed that $(63.9 \%)$ of the nurses experienced nonphysical violence. This occurrence of nonphysical violence was almost five times more than physical violence, where physical violence was among (11.9\%) nurses at the emergency department and nonphysical was among about $64 \%$ nurses in the last 12 months of period [10].

A previous study also mentioned that in their findings the nonphysical abuse among nurses was found very common as work place violence in the emergency departments. They claim that the physical and sexual assault were less in number as compare to verbal violence [12]. Similarly, according to another study, a total of $65.7 \%$ nurses working at the emergency departments were exposed to nonphysical type of violence at their work place which is somewhere in accordance with this current study findings [13].

During this current study almost half of the physical violence $13.61 \%$ (out of $22 \%$ ) was done by the relatives of patients, which becomes almost half the violence.

Similarly, a previous study conducted also found some similar or even more serious findings, where $89.7 \%$ nurses faced nonphysical violence from patients' relatives and $90.5 \%$ of physical violence was from patients' relatives. In the evening shift, the occurrence of violence was very high [13].

Findings of this current study, reveals that the most common physical violence were beating experienced by $4.08 \%$ nurses, pushing experienced by $9.52 \%$ nurses, slaping experienced by $6.12 \%$ of the nurses, pinching by $1.36 \%$ nurses, shooting experienced by $1.36 \%$ participants nurses.

According to previous study, some commonest physical violence were spiting, pushing, kicking and scratching by the patients and their relatives which comprises of almost $50 \%$ of the physical violence occurrence [9].

According to this current study, the type of nonphysical assault the study participants were exposed to in which $50.34 \%$ of participants had experience threats $36.05 \%$ experience verbal abuse and $2.04 \%$ of study participants had experience sexual harassment/abuse and not applicable for $11.56 \%$ of study participants.
Previously, among the verbal violence, the most common (70\%) was yelling from patients and their families, intimidated and being harassed with sexually abusive language [14].

According to another study, threats were also found high among the (35\%) of the study participants [11].

\section{LIMITATIONS}

- Less sample size 147 due to which, the findings cannot be generalized.

- Time was too short, to see any prospective events or detailed associations of awareness and practices.

- Convenient sampling technique was used which may have some biasness.

\section{CONCLUSION}

The purpose of this study was to assess the prevalence of work place violence and types of physical and non physical violence in the public hospitals of Lahore. The emergency nurses during study indicated that violence was a common occurrence.

It was found that $77.55 \%$ stated that they are not exposed to physical violence last 12 months, $13.6 \%$ said once, $7.48 \%$ said 2-3 times and 1.3\% stated they have been exposed 4-5 times during last year. On the other hand the participants exposed to Nonphysical violence in last 12 months, $12.93 \%$ stated that they are not exposed to physical violence last 12 months, $25.85 \%$ said once, $40.82 \%$ said $2-3$ times and $19.73 \%$ stated they have been exposed 4-5 times during last year.

Most recent physical incident in which $10.20 \%$ of incidents were happened at resuscitation room $2.04 \%$ at waiting room and $10.20 \%$ in treatment room. The most recent nonphysical incident in which $38.10 \%$ of incidents were happened at resuscitation room $0.68 \%$ in triage $12.24 \%$ at waiting room and $37.41 \%$ in treatment room $0.68 \%$ in other places.

It was also found that $2.04 \%$ incidents happened at morning shift $9.52 \%$ at evening $8.84 \%$ at night shift. Where as in nonphysical violence $11.56 \%$ incidents happened at morning shift $42.86 \%$ at evening $30.61 \%$ at night shift $3.40 \%$ participants was not sure about timing of the incident.

\section{CONFLICT OF INTEREST}

Declared none.

\section{ACKNOWLEDGEMENTS}

I am highly thankful to Allah, for giving me the strength and knowledge to carry out this research work. Without Allah's blessings and providence, it would not be possible to complete this research project successfully. I am also grateful to my parents and family members, who gave me enough courage and support to complete this work. 


\section{REFERENCES}

[1] Blanchar Y. Violence in the health care sector: A global issue. World Med J 2011; 57(3): 87-9.

[2] Mitchell A, Ahmed A, Szabo C. Workplace violence among nurses, why are we still discussing this? Literature review. J Nurs Educ Pract 2014; 4(4): 147.

DOI: $10.5430 /$ jnep.v4n4p147

[3] Boafo IM, Hancock P. Workplace violence against nurses: A cross-sectional descriptive study of Ghanaian nurses. SAGE Open 2017; 7(1): 1-9. DOI: 10.1177/2158244017701187

[4] Lanctôt N, Guay S. The aftermath of workplace violence among healthcare workers: A systematic literature review of the consequences. Aggress Violent Behav 2014; 19(5): 492-501. DOI: 10.1016/j.avb.2014.07.010

[5] Alameddine M, Mourad Y, Dimassi H. A national study on nurses' exposure to occupational violence in Lebanon: Prevalence, consequences and associated factors. PloS One 2015; 10(9): e0137105. DOI: 10.1371/journal.pone.0137105

[6] Somani RK. Workplace violence towards nurses: A reality from the Pakistani context. J Nurs Educ Pract 2012; 2(3): 148. DOI: $10.5430 /$ jnep.v2n3p148

[7] Baydin A, Erenler AK. Workplace violence in emergency department and its effects on emergency staff. Int J Emerg Ment Health 2014; 16(2): 288-90. DOI: $10.4172 / 1522-4821.1000112$
[8] KowalenkoT, Hauff SR, Morden PC, Smith B. Development of a data collection instrument for violent patient encounters against healthcare workers. West J Emerg Med 2012; 13(5): 429. DOI: $10.5811 /$ westjem.2011.12.6795

[9] Gacki-Smith J, Juarez AM, Boyett L, Homeyer C, Robinson L, MacLean SL. Violence against nurses working in US emergency departments. J Healthc Prot Manage 2010; 26(1): 81-99.

[10] Albashtawy M. Workplace violence against nurses in emergency departments in Jordan. Int Nurs Rev 2013; 60(4): 550-5. DOI: 10.1111/inr.12059

[11] Imran N, Pervez MH, Farooq R, Asghar AR. Aggression and violence towards medical doctors and nurses in a public health care facility in Lahore, Pakistan: A preliminary investigation. Khyber Med Univ J 2013; 5(4): 179-84.

[12] Cheung T, Yip PS. Workplace violence towards nurses in Hong Kong: Prevalence and correlates. BMC Public Health 2017; 17(1): 196. DOI: 10.1186/s12889-017-4112-3

[13] Abdellah RF, Salama KM. Prevalence and risk factors of workplace violence against health care workers in emergency department in Ismailia, Egypt. Pan Afr Med J 2017; 26(1): 1-8. DOI: 10.11604/pamj.2017.26.21.10837

[14] Gacki-Smith J, Juarez AM, Boyett L, Homeyer C, Robinson L, MacLean SL. Violence against nurses working in US emergency departments. J Nurs Admin 2009; 39(7/8): 340-9. DOI: 10.1097/NNA.0b013e3181ae97db 